Original Article

\title{
TRENDS IN PRESCRIPTION PATTERN IN MEDICAL INDIAN ICU AND IT'S IMPACT ON PATIENT OUTCOME
}

\author{
VENKAT RAMAN KOLAa, MEDA HEMASREE ${ }^{b}$, SHARON ROSE $^{b}$, KISHORE $^{b}$
}

aDepartment of Critical Care Medicine, Yashoda Hospital, SP Road, Secunderabad, Telangana, India, 500003, bDepartment of Pharmacy, Anurag Group of Institutions, Venkatapur, Ghatkesar, Medchal, Hyderabad, Telangana, India, 5000088

Email: dr_kvraman@yahoo.co.in

Received: 16 Oct 2021, Revised and Accepted: 30 Nov 2021

ABSTRACT

Objective: The objective of this study is to evaluate the trends in prescribing pattern in medical ICU concerning patient age, gender, past, and current illness along with comorbidities for the evasion of polypharmacy and to improve patient outcomes.

Methods: A prospective analysis of the case records of patients admitted to the ICU of Yashoda hospital in India was carried out.

Results: 120 patients were evaluated, consisting of $77 \%$ male patients. The mean \pm SD of age is $53.81 \pm 14.63$. The majority of the study subjects belonged to the age group of 50-67 y (32\%) Most common causes for admission to the ICU were Respiratory diseases and Stroke. Diabetes mellitus and Hypertension are the most common co-morbidities identified. The total number of drugs used were 1502 during this study period. The average number of drugs per prescription is 12 . The range is between 2-30. The average number of antibiotics per prescription is 3. Commonly prescribed drug classes were the GI agents in $100 \%$ of patients, followed by antimicrobial agents (AMAs) in $95.8 \%$ of patients. About $42.5 \%$ of patients received 3 antibiotics per day. 55 potential drug-drug interactions were interpreted in 46 patients. 30(55\%) were moderate interactions 25(45\%) were major interactions, which were addressed. De-escalation of antibiotics was seen in $29 \%$ of patients while escalation in $13 \%$. The death rate is only $5 \%$ in our ICU setting.

Conclusion: This prescription pattern study can provide a framework for continuous prescription audit in the ICU

Keywords: Prescription pattern, Intensive care unit, Antimicrobial agents

(C) 2022 The Authors. Published by Innovare Academic Sciences Pvt Ltd. This is an open access article under the CC BY license (https://creativecommons.org/licenses/by/4.0/) DOI: https://dx.doi.org/10.22159/ijpps.2022v14i1.43387. Journal homepage: https://innovareacademics.in/journals/index.php/ijpps.

\section{INTRODUCTION}

The Intensive Care Unit is a setting where a large number of drugs are administered to most of the patients due to their critical illness and multiple complexities [1]. The medical ICUs represent an important platform for conducting prescription pattern studies as they explain the extent and profile of drug use, trends, and impact on patient outcomes [2].

Prescription pattern study provides insights regarding drug use. Quality of life can be improved by enhancing the standards of medical treatment and that can only be assessed by prescription pattern study because it is based on documented evidence to support diagnosis, treatment, and justified utilization of hospital facilities [3]. There is an increasing importance of prescription pattern study because of boost in marketing of new drugs, variation in the pattern of prescribing and consumption of drugs leading to growing concern to provide the best healthcare [2]. Analyses of prescription patterns will help in the evasion of polypharmacy and improve patient outcomes.

Polypharmacy can lead to Drug-drug interactions, increased drug adverse effects, medication errors, and high cost. Appropriateness of polypharmacy in ICU and its implication on patient outcome is always a debated issue among Healthcare professionals. Multiple anti-microbial and their rational use in ICU is a challenging issue.

The main objective of this study is to evaluate the prescribing patterns concerning patient age, gender, past, and current illness along with co-morbidities. Other objectives of the study were to assess the appropriateness of drugs ordered based on patient diagnosis to determine the number of drugs prescribed, and to compute the average number of medicines per prescription, to ascertain the patient's outcome, and to assess the possible drug interactions found in the prescription.

\section{MATERIALS AND METHODS}

Study design and data collection

The case records of 120 patients admitted to the ICU at a tertiary hospital in India were analyzed in this prospective and observational study. Data collection was done using a pre-designed proforma. The variables collected were demographic and clinical characteristics. We also considered the indication and utilization of different drugs.

\section{Inclusion criteria}

Patients between the ages of 16 and $90 \mathrm{y}$ old suffering from multiple illness who had been admitted in the ICU and patients who require special assistance are included in this study.

\section{Exclusion criteria}

Patients who are under the age of $15 \mathrm{y}$, pregnant or nursing mothers and patients with a limited stay $(<24 \mathrm{~h})$ in the CCU are excluded from the study.

Ethical approval was obtained from the Anurag group of Institutions. This approval provides permission to utilize patients' data in a confidential manner without disclosing patients' details

Approval No: IRB-AGI/2020-2021 PROPOSAL No.: 2

\section{Statistical analysis}

After the collection of data, it was entered in a Microsoft Excel sheet and verified. A clean data sheet was generated and the analysis was done in SPSS. Descriptive statistics were used to describe the data. The analyses were performed using an Independent t-test, Fishers's exact test, Pearson correlation test whenever appropriate. Confidence interval is $95 \%$, hence P-value $<0.05$ is considered significant. 


\section{RESULTS}

We collected the data of 120 prescription forms of the patients who were admitted to ICU. Our study showed the following results when we observed the demographic profile of the patients. The study revealed that male patients were more in number $(77 \%)$ compared to female patients (23\%). The majority of prescriptions $(32 \%)$ belonged to patients of 58-67 y age group; the mean \pm SD of age is 53.81 \pm 14.63 . (table 1 and table 2 explain the aforementioned observations).

The observed disease pattern was variable. Diseases of the respiratory system were maximum $20.70 \%$ followed by neurological diseases $19.90 \%$; infectious diseases were $18.20 \%$, diseases of GI were $7.30 \%$, RTA and poisoning were $5.00 \%$ each, malignant cases were $3.30 \%$, renal disorders and hematology disorders are $1.60 \%$ each. (table 3 explain the above results). Diabetes mellitus (24\%) and systemic hypertension (20\%) were the most common underlying co-morbid conditions (table 4 explain about these details).

Table 1: Age distribution

\begin{tabular}{lll}
\hline Age interval (years) & $\mathbf{N = 1 2 0}$ & Percentage (\%) \\
\hline $18-27$ & 9 & 7 \\
$28-37$ & 7 & 6 \\
$38-47$ & 20 & 17 \\
$48-57$ & 27 & 22 \\
$58-67$ & 38 & 32 \\
$68-77$ & 15 & 13 \\
$78-87$ & 4 & 3 \\
\hline
\end{tabular}

The mean \pm SD of age is $53.81 \pm 14.63$

Table 2: Gender wise distribution

\begin{tabular}{llll}
\hline Gender & N (\%) & Median & mean \pm SD \\
\hline Male & $92(77)$ & 55.5 & $53.98 \pm 14.41$ \\
Female & $28(23)$ & 55.5 & $53.25 \pm 15.57$ \\
\hline
\end{tabular}

It indicates that there is no statistically significant difference in the mean age between male and female patients.

Table 3: Diagnostic criteria

\begin{tabular}{|c|c|c|}
\hline Diagnosis & No of patients & Percentage (\%) \\
\hline Respiratory & 25 & $20.70 \%$ \\
\hline COVID & 4 & $3.30 \%$ \\
\hline Pneumonia & 6 & $5.00 \%$ \\
\hline COPD & 1 & $0.80 \%$ \\
\hline RF-II & 7 & $5.80 \%$ \\
\hline LRTI & 7 & $5.80 \%$ \\
\hline Neuro & 24 & $19.90 \%$ \\
\hline Stroke & 20 & $16.60 \%$ \\
\hline Seizures & 4 & $3.30 \%$ \\
\hline Infectious diseases & 22 & $18.20 \%$ \\
\hline Cellulitis & 2 & $1.60 \%$ \\
\hline Sepsis & 17 & $14.10 \%$ \\
\hline ТВ & 3 & $2.50 \%$ \\
\hline Others & 19 & $15.80 \%$ \\
\hline GI & 9 & $7.30 \%$ \\
\hline Acute ge & 4 & $3.30 \%$ \\
\hline CLD & 2 & $1.60 \%$ \\
\hline Jaundice & 1 & $0.80 \%$ \\
\hline Pyloric obstruction & 1 & $0.80 \%$ \\
\hline GI Bleed & 1 & $0.80 \%$ \\
\hline RTA & 6 & $5.00 \%$ \\
\hline Poisoning & 6 & $5.00 \%$ \\
\hline Malignancy & 4 & $3.30 \%$ \\
\hline Renal disorders & 2 & $1.60 \%$ \\
\hline CKD & 2 & $1.60 \%$ \\
\hline Hematology & 2 & $1.60 \%$ \\
\hline Vascular injury & 2 & $1.60 \%$ \\
\hline CVS & 1 & $0.80 \%$ \\
\hline Cardiogenic shock & 1 & $0.80 \%$ \\
\hline
\end{tabular}

Table 4: Comorbidities exist in the study population

\begin{tabular}{lll}
\hline Comorbidity & No. of patients & Percentage \\
\hline Diabetes mellitus & 29 & 24 \\
Hypertension & 24 & 20 \\
Chronic kidney disease & 5 & 4 \\
Chronic liver disease & 1 & 1 \\
Cancer & 3 & 3 \\
Hypothyroidism & 6 & 5 \\
CAD & 9 & 8 \\
COPD & 3 & 3 \\
Asthma & 2 & 2 \\
Seizures & 3 & 3 \\
Post COVID & 10 & 8 \\
\hline
\end{tabular}


120 patients were included in the study. The total no of drugs is 1502. The average number of drugs per patient is 12 , with a maximum number of 30 drugs per patient and a minimum number of drugs per patient was 4 . (table 5.1 explains these details).

About $45.8 \%$ of patients received prescriptions in the range of $11-15$ drugs, $4.2 \%$ of patients received no antibiotics, 1 antibiotic was prescribed in $20.80 \%$ of patients, $2,3,4$ antibiotics were prescribed in $30.8 \%, 42.6 \%, 1.6 \%$ patients, respectively. (table 5.2, table 5.3 and fig. 1 explain these details).

\section{Polypharmacy}

Table 5.1: Details of prescription

\begin{tabular}{ll}
\hline Details of prescription & Number \\
\hline Total no of drugs & 1502 \\
Maximum no of & 30 \\
drugs/prescription & \\
Average no of drugs/prescription & 12 \\
Minimum no of drugs/prescription & 4 \\
\hline
\end{tabular}

Table 5.2: No of drugs/prescription

\begin{tabular}{lllll}
\hline No of drugs/prescription & Male & Female & Total & Percentage (\%) \\
\hline $0-5$ & 3 & 3 & 6 & 5 \\
$6-10$ & 25 & 17 & 52 & 26.6 \\
$11-15$ & 44 & 11 & 23 & 45.8 \\
$16-20$ & 17 & 6 & 2 & 19.4 \\
$21-25$ & 2 & 0 & 2 & 1.6 \\
$26-30$ & 2 & 0 & 1.6 & \\
\hline
\end{tabular}

Table 5.3: No of antibiotics/day

\begin{tabular}{lll}
\hline No of antibiotics/day & No of patients & Percentage (\%) \\
\hline 0 & 5 & $4.2 \%$ \\
1 & 25 & $20.8 \%$ \\
2 & 37 & $30.8 \%$ \\
3 & 51 & $42.6 \%$ \\
4 & 2 & $1.6 \%$ \\
\hline
\end{tabular}

The most common drug groups prescribed were GI drugs given in 120 patients, Multi-vitamins 117, Antibiotics 115, Others 114, CVS 75, anti-platelets and anti-coagulants 69, sedatives 69, Antiepileptics 51, Respiratory drugs 33, anti-pyretics 31. GI and DVT prophylaxis was given in $100 \%$ and $47.5 \%$ of patients respectively, (table 6 and table 7 and fig. 2 explain these details).

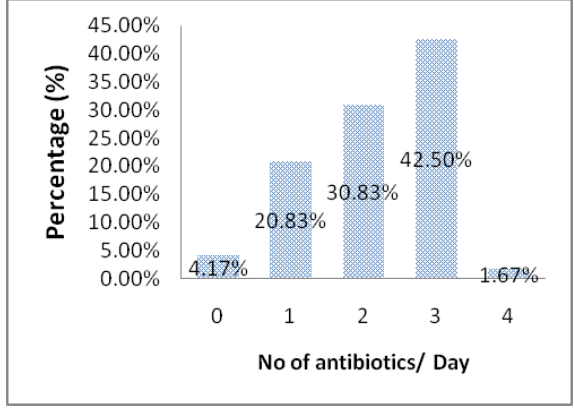

Fig. 1: No of antibiotics/Prescription/Day

Table 6: Categories of drugs

\begin{tabular}{lllll}
\hline Category & Maximum & Average & Total & No of patients \\
\hline GI & 6 & 1 & 168 & 285 \\
Multi-vitamins & 3 & 2 & 326 & 117 \\
Antibiotics & 4 & 3 & 218 & 115 \\
Others & 2 & 1 & 172 & 114 \\
CVS & 7 & 2 & 99 & 75 \\
Anti-platelets and anti-coagulants & 4 & 1 & 73 & 69 \\
Sedatives & 3 & 1 & 54 & 51 \\
Anti-epileptics & 3 & 1 & 59 & 33 \\
Respiratory drugs & 3 & 2 & 38 \\
Analgesics and Anti-pyretics & 2 & 1 & \\
\hline
\end{tabular}

Table 7: Prophylactic indication

\begin{tabular}{lll}
\hline & No. of patients & Percentage (\%) \\
\hline GI prophylaxis & 120 & $100 \%$ \\
DVT prophylaxis & 57 & $47.5 \%$ \\
\hline
\end{tabular}

The prescriptions were also studied for possible drug-drug interactions. We found a total of 55 potential drug-drug interactions, $25(45 \%)$ were major and 35(55\%) were moderate Drug-Drug interactions. Details of the possible Major Drug-Drug interactions are shown in the following fig. 3. There was at least one potential drug-drug interactions per prescription in $69 \%$ of patients, 2 and 3 were seen in $25.6 \%$ and $5.4 \%$ of patients, respectively (table 8) shows the details).

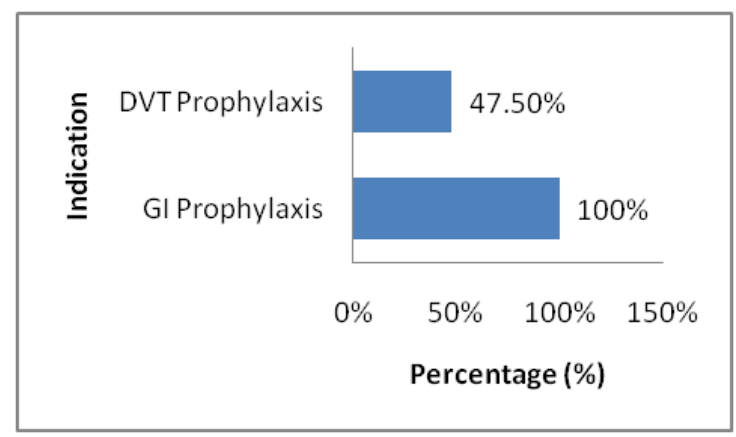

Fig. 2: Prophylactic indication

Table 8: No of interactions/prescription

\begin{tabular}{llll}
\hline No of interactions/prescription & Total no of patients & Percentage (\%) & SAE/AE \\
\hline 1 & 38 & 69 & NIL \\
2 & 7 & 25.6 & NIL \\
3 & 1 & 5.4 & NIL \\
\hline
\end{tabular}




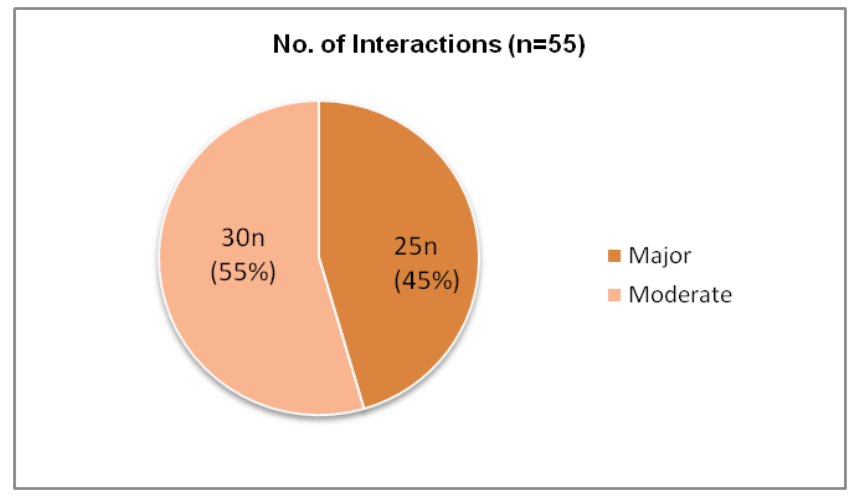

Fig. 3: Severity of interaction

It was found that the most commonly administered antibiotic in ICU in our setting is cefaperazone+salbactum $18.71 \%$, followed by meropenem $14.11 \%$, Teicoplanin 7.36\%, Clindamycin 7.36\%, Metronidazole $6.13 \%$, Polymixin B 4.60\%, Ceftriaxone-3.99\%, Fluconazole and Doxycycline
$3.68 \%$ each, Cefuroxime $2.76 \%$, Piperacillin+tazobactum $2.76 \%$, Colistin $2.15 \%$, Sulphamethazole+Trimethoprim and Voriconazole $2.15 \%$ each, Minocycline and Vancomycin 1.84\% each, Linezolid 1.53\%, (table 9 shows the details).

Table 9: Antibiotics prescribed In ICU

\begin{tabular}{|c|c|c|}
\hline Antibiotic & No. of patients & Percentage (\%) \\
\hline Cefaperazone+salbactum & 61 & $18.71 \%$ \\
\hline Meropenem & 46 & $14.11 \%$ \\
\hline Teicoplanin & 24 & $7.36 \%$ \\
\hline Clindamycin & 23 & $7.06 \%$ \\
\hline Metronidazole & 20 & $6.13 \%$ \\
\hline Polymixin B & 15 & $4.60 \%$ \\
\hline Ceftriaxone & 13 & $3.99 \%$ \\
\hline Fluconazole & 12 & $3.68 \%$ \\
\hline Doxycycline & 12 & $3.68 \%$ \\
\hline Cefuroxime & 9 & $2.76 \%$ \\
\hline Piperacillin+tazobactum & 9 & $2.76 \%$ \\
\hline Colistin & 7 & $2.15 \%$ \\
\hline Sulphamethazole+Trimethoprim & 7 & $2.15 \%$ \\
\hline Voriconazole & 7 & $2.15 \%$ \\
\hline Minocycline & 6 & $1.84 \%$ \\
\hline Vancomycin & 6 & $1.84 \%$ \\
\hline Linezolid & 5 & $1.53 \%$ \\
\hline Clarithromycin & 4 & $1.23 \%$ \\
\hline Ceftazidine & 3 & $0.92 \%$ \\
\hline Tigecycline & 3 & $0.92 \%$ \\
\hline Amoxicillin & 3 & $0.92 \%$ \\
\hline Amikacin & 2 & $0.61 \%$ \\
\hline Ampicillin & 2 & $0.61 \%$ \\
\hline Azithromycin & 2 & $0.61 \%$ \\
\hline Cefipime+Tazobactum & 2 & $0.61 \%$ \\
\hline Fosfomycin & 2 & $0.61 \%$ \\
\hline Imipenem & 2 & $0.61 \%$ \\
\hline Levofloxacin & 2 & $0.61 \%$ \\
\hline Amoxicillin+clavulanic acid & 2 & $0.61 \%$ \\
\hline Cefipime & 2 & $0.61 \%$ \\
\hline Cefixime & 2 & $0.61 \%$ \\
\hline Cefotaxime & 2 & $0.61 \%$ \\
\hline Gentamicin & 2 & $0.61 \%$ \\
\hline Imipenem+cilastatin & 2 & $0.61 \%$ \\
\hline Amidlafugin & 1 & $0.31 \%$ \\
\hline Aztreonam & 1 & $0.31 \%$ \\
\hline Cefotaxime+salbactum & 1 & $0.31 \%$ \\
\hline Ceftraixone+salbactum & 1 & $0.31 \%$ \\
\hline Isavuconazole & 1 & $0.31 \%$ \\
\hline Ivermectin & 1 & $0.31 \%$ \\
\hline
\end{tabular}

Table 10: Indication of antimicrobial Use

\begin{tabular}{|c|c|c|}
\hline Indication & No. of patients & Percentage (\%) \\
\hline Prophylactic & 47 & 39 \\
\hline Empirical & 11 & 9 \\
\hline Confirmatory & 62 & 52 \\
\hline
\end{tabular}


In our analysis, the most prevalent indication for antibiotic usage is confirmatory (52\%) - it is deemed an indication if clinical and/or laboratory results show proof of infection. Following that, prophylactic (39\%) and empirical usage (9\%), (table 10) show the details.

There was no escalation or de-escalation for 58 percent of patients. Overall, antibiotics were escalated in $13 \%$ of cases while deescalated in $29 \%$ of cases. It is shown in fig. 4.

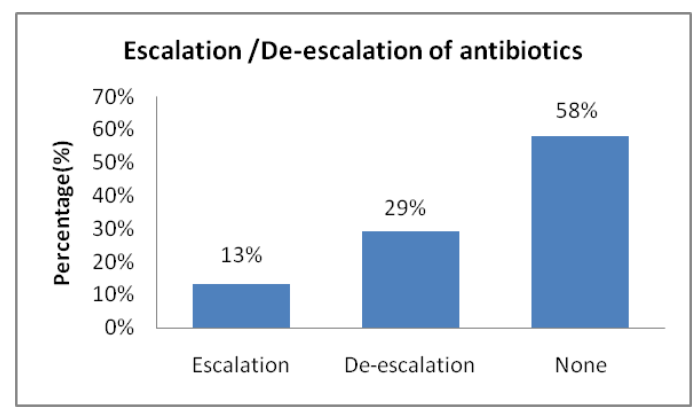

Fig. 4: Escalation/De-escalation of antibiotics

In terms of patient outcomes, during their stay in the ICU, $67 \%$ were transferred to general wards, 5 percent died, and 28 percent were discharged directly from the ICU (table 11).

Table 11: Outcomes of treatment

\begin{tabular}{lll}
\hline Outcome & No. of patients & Percentage (\%) \\
\hline Discharged & 34 & 28 \\
Shifted to ward & 80 & 67 \\
Death & 6 & 5 \\
\hline
\end{tabular}

\section{DISCUSSION}

In the present study, we studied 120 patients' prescriptions admitted to ICU. $32 \%$ of patients were mostly grouped within the age of $58-67 \mathrm{y}$ as shown in table 1 . The mean \pm SD of age is 53.81 \pm 14.63 ; among 120 patients, 92(77\%) were male and 28(23\%) were female. This difference could be due to geographic variation in disease occurrence. In a study done by Al-zakwani et al., they found that among 138 patients admitted to the ICU during the 5-month study period revealed that the mean age of the patients was $46 \pm 19 \mathrm{y}$, with males representing $64 \%$ of the patients [5]. This finding was similar to the two studies conducted in eastern and southern India in 2007 and 2011 [1].

The most common illnesses, accounted for ICU admission in the study were respiratory disorders followed by neurological disorders, which is similar to a study in Nepal where the most common causes were chronic obstructive pulmonary disease, cerebrovascular accident, and myocardial infarction [9].

Diabetes mellitus (24\%) and systemic hypertension (20\%) were the most common underlying co-morbid conditions and this adds to the existing body of evidence that these diseases are assuming epidemic proportions in developing countries. It is similar to a study conducted by Rajathilagam et al. in a medical ICU of a tertiary care teaching hospital of south India [11].

120 patients were included in the study. The total no of drugs is 1502. The average number of drugs per patient was 12.0 with a maximum number of 30 drugs and a minimum number of drugs 4 . This is comparable to other previous studies. In an American study conducted in a trauma ICU, the average number of prescribed drugs was 9.1 while an Indian study showed an average of 13.5 drugs [6].

The average number of drugs per person is an important index of trends in a prescription pattern. It is preferable to keep the mean number of drugs per prescription as low as possible since high fig. always lead to increased risk of drug interactions, polymicrobial use may cause the development of bacterial resistance, and increased hospital cost.

It is noted that a total number of antibiotics prescribed were 326 in 120 prescriptions; the maximum number of antibiotics prescribed per prescription was 4 at a time. The average number of antibiotics per prescription was 3 during the hospital stay.

About $95.8 \%$ of the patients received antibiotics, and the average number of AMAs per patient was 3. About $20.83 \%$ of patients received one AMA; another $30.83 \%$ received two AMAs, $42.50 \%$ were administered three AMAs and $1.67 \%$ were given four AMAs. This is similar to a study where $77 \%$ of the ICU patients were given 1-3 AMAs, 23\% were given 4-8 AMAs [8]. In our study, patients received more than one AMA as some of the patients were suffering from mixed infections; three or more AMAs are used to treat Grampositive, Gram-negative, and anaerobic infections. In many instances, antibiotic change is as per the culture sensitivity tests.

Polypharmacy was visible in our data. The maximum number of prescriptions i.e. $45.8 \%$ had $11-15$ drugs, followed by $6-10$ in $26.6 \%$ and 16-20 drugs in $19.4 \%$. Polypharmacy is a very common practice nowadays as it is reported by various studies. It is of concern in those patients with various co-morbidities as it increases the chances of drug interactions. Though it is polypharmacy, there is a need for empirical therapy until definitive diagnosis becomes clear and multiple drug usage is essential for the management of acute life-threatening conditions. In addition, patients who are admitted to the ICU may have more than one disease, and treating all of them effectively with multiple drugs can lead to better outcomes.

The total number of GI drugs includes 168, of which pantoprazole $(100 \%)$ is most commonly prescribed drug. A study in Western Nepal found that pantoprazole was the most frequently prescribed [7]. The total no of CVS drugs includes 172 out of which Atorvastatin and Metoprolol are the most common drugs prescribed, on average, the CVS drugs per prescription was 2. Under the anti-platelets and anti-coagulants drugs, the most common drug is enoxaparin, which was given for about $47.5 \%$ of patients i.e. indicated for DVT prophylaxis. The most common respiratory drug prescribed is salbutamol as nebulization. On average 2 drugs per prescription were prescribed. Levetiracetam is the most common Anti-epileptic prescribed. The maximum number of multi-vitamins per prescription includes 3 and on average 2 were prescribed; the most common drug is Optineuron.

While analyzing the prescriptions for possible drug-drug interactions, 55 drug-drug interactions were interpreted in 46 patients. Most of them were moderate 30 (55\%) followed by major interactions 25 (45\%). Drug interactions can be potentially hazardous but most of the consequences of interactions can be overcome with careful monitoring of the patient. When evaluating DIs, one primary concern was the clinical significance or level of severity of the interaction. Even though a large number of potential DIs were identified in this study, they were no clinically significant events and only required the monitoring of patients. Various interventions can be made for DIs, such as substituting the drug, stopping or avoiding or adjusting the dose, and monitoring of DI effects. Most of the interventions were to monitor patient parameters such as renal function, liver function, electrolyte levels, monitoring for CNS and respiratory depression; however, such things were routinely carried out in the ICU even before the commencement of this study.

It was reported in our study that there was one interaction per prescription accounting for 38 patients (69\%) whereas, two interactions per prescription and three interactions per prescription were seen in for $7(25.6 \%)$ and $1(5.4 \%)$.

The most common AMA's prescribed was cefoperazone+sulbactum 18.71\%; Meropenem 14.11\% Teicoplanin 7.36\% Clindamycin 7.06\% Metronidazole $6.13 \%$. This is similar to an ICU study in Maharashtra, which reported the use of cephalosporins and aminoglycosides in $65.33 \%$ and $27.5 \%$ of the individuals on AMA therapy but differed from another study in which the penicillins were the most common 
antimicrobial drug class prescribed [9]. Cephalosporins are commonly prescribed due to their relatively lower toxicity and broader-spectrum activity.

In our analysis, the most prevalent indication of AMA therapy was confirmatory (52\%), which is deemed an indication of clinical or laboratory results showing evidence of infection. Following which were prophylactic (39\%) and empirical (9\%) indications.

Overall, escalation is seen in $13 \%$ of cases where de-escalation occurred in $29 \%$ of cases. When a significant pathogen was isolated, escalation occurred more frequently, in contrast to most individuals with no pathogen had no change in therapy.

The outcomes of the patients during their stay in ICU is about $67 \%$ of patients were shifted to a ward while $5 \%$ were deceased.

\section{LIMITATIONS}

Our study has limitations, as it was a prospective observational study; the sample size is relatively small in the mixed ICU, which may not fully reflect the accurate population characteristics and the assessment of medication errors was not assessed.

\section{CONCLUSION}

In our study, we studied the Prescription pattern in a tertiary care medical ICU managing critical illness. The average number of drugs is 12 per prescription, indicating polypharmacy, as the patients in ICU are critically ill with multiple complexities. It was seen that a variety of drugs from various drug classes were used for a wide spectrum of clinical diagnoses. Respiratory disorders were the most common cause of ICU admission. Hypertensive and Diabetes mellitus are the most common co-morbidities observed. GI drugs and Antimicrobials are commonly used drugs in ICU. PPI(Pantoprazole is prescribed in all the patients as GI prophylactic therapy). In addition, to avoid antibiotic resistance, de-escalation is done where necessary. Even after the 55 potential drug interactions i.e., moderate $35(55 \%)$ and major $25(45 \%)$ were analyzed and addressed there is no clinical significant event observed. The $95 \%$ of patients either has been discharged or shifted to other wards and death is seen in $5 \%$ of the study population. This prescription pattern study can provide a framework for continuous prescription audits in the ICU for improving patient oucomes.

\section{ABBREVIATIONS}

ICU-Intensive Care Unit, AMA-Anti-microbial agents, CVSCardiovascular System, CNS-Central nervous system, GIGastrointestinal, DVT-Deep vein thrombosis, NSAID-Non-steroidal anti-inflammatory drugs, DI-Drug Interaction

\section{FUNDING}

Nil

\section{AUTHORS CONTRIBUTIONS}

Dr. Venkat Raman Kola designed the study and drafted the manuscript; Meda Hemasree and Sharon Rose raised the idea, participated in the study conception and manuscript revision, collected the data from the hospital and was also involved in statistical analysis, Kishore collected the data from the hospital and also involved in statistical analysis.

\section{CONFLICT OF INTERESTS}

\section{Declared none}

\section{REFERENCES}

1. Patanaik SK, Pattanayak C, Prasad A, Chauhan AS. Drug utilization pattern in an intensive care unit setting in Eastern India. Int J Basic Clin Pharmacol 2003;4(6):1136-41. doi: 10.18203/2319-2003.ijbcp20151347.

2. Nagashree BN, Manchukonda RS. Prescription audit for evaluation of present prescribing trends in a rural tertiary care hospital in South India: an observational study. IJBCP. 2016 Sep-Oct;5(5):2094-7. doi: http://dx.doi.org/10.18203/23192003.ijbcp20163242.
3. Kaur SJ, Rajagopalan S, Kaur N, Shafiq N, Bhalla A, Pandhi P, Malhotra S. Drug utilization study in the medical emergency unit of a tertiary care hospital in North India hindawi publishing corporation. Emerg Med Int 2014;5. https://doi.org/ 10.1155/2014/973578

4. Sunny D, Roy K, Benny SS, Mathew DC, Gangadhar Naik J, Gauthaman K. Prescription audit in an outpatient pharmacy of a tertiary care teaching hospital-a prospective study. J Young Pharm. 2019;11(4):417-20. doi: 10.5530/jyp.2019.11.85.

5. Al-Zakwani I, Al-Thuhli M, Al-Hashim A, Al Balushi KA. Drug utilization pattern in an intensive care unit at a tertiary care teaching hospital in Oman. Asian J Pharm Clin Res. 2017;10(2):194-7. doi: 10.22159/ajpcr.2017.v10i2.15148.

6. Patel MK, Barvaliya MJ, Patel TK, Tripathi C. Drug utilization pattern in critical care unit in a tertiary care teaching hospital in India. Int J Crit Illn Inj Sci. 2013 Oct-Dec;3(4):250-5. doi: 10.4103/2229-5151.124128, PMID 24459622.

7. Paudel R, Palaian S, Bishnurath G, Hom KC, Anil KS, Poudel A, Khanal S, Shankar PR. Clinical profile and drug utilization pattern in an intensive care unit of a teaching hospital in Western Nepal. Arch Pharm Pract. 2011;2(4):163-9.

8. Nibrad VV, Nayak BB, Raul AR, Vijayprasad S, Vakade KP, Jadhav AR. Drug utilization pattern in a medical intensive care unit (MICU) in a tertiary care teaching hospital in rural area of Maharashtra. Int J Appl Biol Pharm Technol. 2015;6(1):148-53.

9. Shankar PR, Partha P, Dubey AK, Mishra P, Deshpande VY. Intensive care unit drug utilization in a teaching hospital in Nepal. Kathmandu Univ Med J (KUMJ). 2005;3(2):130-7. PMID 16415608.

10. Panda RK, Abhisek PA, Sika LM, Pradhan SS, Routray SS, Mohanty S. Utilisation of antimicrobial agents in intensive care unit at a tertiary care teaching hospital in eastern India. Int J Basic Clin Pharmacol 2019 Sep;8(9). doi: 10.18203/23192003.ijbcp20193672.

11. Rajathilagam AR, Malathy SS, Kothai G. Prescription pattern in a medical ICU of a tertiary care teaching hospital of south India. BPJ. 2018;11(1):405-10.

12. Pichala PT, Mukkillapati BK, Thomas SZD, Saunchez L. Gerardo $\mathrm{AU}$ an interventional study on intensive care unit drug therapy assessment in a rural district hospital in India. JBCP. 2013;4(3).

13. Chatterjee S, Mandal A, Lyle N, Mukherjee S, Singh AK. Drug utilization study in a neonatology unit of atertiary care hospital in eastern India. Pharmacoepidemiol Drug Saf. 2007;16(10):1141-5. doi: 10.1002/pds.1469, PMID 17823977.

14. John L, Devi P, John J, Guido S. Drug utilization study of antimicrobial agents in medical intensive care unit of a tertiary care hospital. AJPCR 2011;4:814.

15. Abideen S, Vivekandan K, Mishra $P$. Assessment of the prevalence of potential drug-drug interactions in medical intensive care unit of a tertiary care hospital in India. AJPCR. 2015;8:125-30.

16. Barot PA, Malhotra SD, Rana DA, Patel VJ, Patel KP. Drug utilization in emergency medicine department at a tertiary care teaching hospital: A prospective study. J Basic Clin Pharm. 2013;4(4):78-81. doi: 10.4103/0976-0105.121650, PMID 24808677.

17. Mali NB, Deshpande SP, Tullu MS, Deshmukh CT, Gogtay NJ, Thatte UM Mali. A prospective antibacterial utilization study in pediatric intensive care unit of a tertiary referral center. Indian J Crit Care Med. 2018 Jun;22(6):422-6. doi: 10.4103/ijccm.IJCCM_365_17, PMID 29962742.

18. Williams A, Mathai AS, Phillips AS. Antibiotic prescription patterns at admission into a tertiary level intensive care unit in Northern India. J Pharm Bioallied Sci. 2011;3(4):531-6. doi: 10.4103/0975-7406.90108, PMID 22219587.

19. Bobek M, Hoffman Hogg L, Bair N, Mion L, Arroliga A, Slomka J. Utilization patterns, relative costs, and length of stay following adoption of MICU sedation guidelines. Formulary. 2001;36:664-73.

20. Remesh A, Retnavally K, Salim S, Gayathri A, Nair U. Antibiotics prescribing pattern in the in-patient departments of a tertiary care hospital. Arch Pharma Pract. 2013;4(2):71-6. doi: 10.4103/2045-080X.112987. 
21. Badar VA, Navale SB. Study of prescribing pattern of antimicrobial agents in medicine intensive care unit of a teaching hospital in Central India. J Assoc Physicians India. 2012;60:20-3. PMID 23029737.

22. Askari M, Eslami S, Louws M, Dongelmans D, Wierenga $P$, Kuiper R, Abu-Hanna A. Relevance of drug-drug interaction in the ICU- perceptions of intensivists and pharmacists. Stud Health Technol Inform. 2012;180:716-20. PMID 22874285.

23. Ujwala P, Gawali UP, Khobragade RS. Drug utilization and prescription pattern study in medicine intensive care unit at tertiary care teaching hospital. NJPPP. 2019;9(7):674-7.

24. Mukhopadhyay D, Dudhraj V, Mukherjee D. A descriptive study on the prescription audit of prescribing patterns in primary, secondary, tertiary healthcare facilities in India. ISBN; 2020 Nov: 979-8566362175.
25. Nourmand N, Thomas S. Prescription auditing and study of drug utilization pattern in an outpatient pharmacy of a tertiary care hospital, Bengalu. IAJP. 2018 OctDec;12(4):S119.

26. Afroz A, Gupta S, Saurabh Kansal S, Ramgopal. Prescription auditing and drug utilization pattern in a tertiary care teaching hospital of western. IJBCP. 2012 Dec;1(3):184-90.

27. Badar VA, Navale BSK. Study of prescribing pattern of antimicrobial agents in medicine intensive care unit of a teaching hospital in Central India. JAPI. 2012;60:31.

28. Biswal S, Mishra P, Malhotra S, Puri GD, Pandhi P. Drug utilization pattern in the intensive care unit of a tertiary care hospital. J Clin Pharmacol. 2006;46(8):945-51. doi: 10.1177/0091270006289845, PMID 16855079. 